\title{
Impact of impaired insulin secretion and insulin resistance on the incidence of type 2 diabetes mellitus in a Japanese population: the Saku study
}

\author{
Akiko Morimoto • Yukako Tatsumi • Kijyo Deura • \\ Shoichi Mizuno • Yuko Ohno • Naomi Miyamatsu • \\ Shaw Watanabe
}

Received: 30 December 2012 / Accepted: 22 April 2013 / Published online: 17 May 2013

(C) Springer-Verlag Berlin Heidelberg 2013

\begin{abstract}
Aims/hypothesis To assess the impact of impaired insulin secretion (IIS) and insulin resistance (IR) on type 2 diabetes incidence in a Japanese population.

Methods This 4 year cohort study included 3,059 participants aged 30-69 without diabetes at baseline who underwent comprehensive medical check-ups between April 2006 and March 2007 at Saku Central Hospital. Based on their insulinogenic index and HOMA-IR values, participants were classified by the criteria of the Japan Diabetes Society into four categories: normal; isolated IIS (i-IIS); isolated IR (i-IR); and IIS plus IR. They were followed up until March 2011. The incidence of type 2 diabetes was determined from fasting and $2 \mathrm{~h}$ post-load plasma glucose concentrations and from receiving medical treatment for diabetes.

Results At baseline, 1,550 individuals (50.7\%) were classified as normal, 900 (29.4\%) i-IIS, 505 (16.5\%) i-IR, and 104
\end{abstract}

Electronic supplementary material The online version of this article (doi:10.1007/s00125-013-2932-y) contains peer-reviewed but unedited supplementary material, which is available to authorised users.

A. Morimoto $(\bowtie) \cdot$ Y. Tatsumi $\cdot$ N. Miyamatsu

Department of Clinical Nursing, Shiga University

of Medical Science, Tsukinowa-cho Seta,

Otsu, Shiga 520-2192, Japan

e-mail: aki62@belle.shiga-med.ac.jp

A. Morimoto $\cdot$ Y. Tatsumi $\cdot$ Y. Ohno

Department of Mathematical Health Science, Graduate School

of Medicine, Osaka University, Osaka, Japan

K. Deura $\cdot$ S. Mizuno

Saku Central Hospital, Nagano, Japan

S. Watanabe

Life Science Promoting Association, Tokyo, Japan
(3.4\%) IIS plus IR. During 10,553 person-years of follow-up, 219 individuals developed type 2 diabetes, with 126 (57.5\%) having i-IIS at baseline. Relative to the normal group, the multivariable-adjusted HRs for type 2 diabetes in the i-IIS, iIR and IIS plus IR groups were 8.27 (95\% CI 5.33, 12.83), 4.90 (95\% CI 2.94, 8.17) and 16.93 (95\% CI 9.80, 29.25), respectively. The population-attributable fractions of type 2 diabetes onset due to i-IIS, i-IR, and IIS plus IR were 50.6\% (95\% CI 46.7\%, 53.0\%), 14.2\% (95\% CI 11.8\%, 15.6\%) and $12.9 \%$ (95\% CI 12.3\%, 13.2\%), respectively.

Conclusions/interpretation Compared with IR, IIS had a greater impact on the incidence of type 2 diabetes in a Japanese population.

Keywords Epidemiology · Insulin resistance $\cdot$ Insulin secretion · Japan · Prospective cohort · Type 2 diabetes

$\begin{array}{ll}\begin{array}{l}\text { Abbreviations } \\ \text { AUC }\end{array} \text { glucose0-120 } & \text { AUC of the plasma glucose } \\ \text { FPG } & \text { Fasting plasma glucose } \\ \text { hsCRP } & \text { High-sensitive C-reactive protein } \\ \text { i-IIS } & \text { Isolated impaired insulin secretion } \\ \text { IIS } & \text { Impaired insulin secretion } \\ \text { i-IR } & \text { Isolated insulin resistance } \\ \text { IR } & \text { Insulin resistance } \\ \text { PAF } & \text { Population-attributable fraction } \\ \text { PG } & \text { Plasma glucose } \\ \text { ROC } & \text { Receiver operating characteristic }\end{array}$

\section{Introduction}

The incidence of type 2 diabetes is significantly increasing in Asia, including Japan, China, and Indonesia [1]. Furthermore, Asian Americans have been found to be at 
significantly higher risk of type 2 diabetes than whites, despite having substantially lower BMI [2]. The mean BMI of patients with type 2 diabetes has been found to differ in human populations, being $32.2 \mathrm{~kg} / \mathrm{m}^{2}$ in the USA, $29.4 \mathrm{~kg} / \mathrm{m}^{2}$ in the UK and $23.1 \mathrm{~kg} / \mathrm{m}^{2}$ in Japan [3-5].

Impaired insulin secretion (IIS) and insulin resistance (IR) are the main pathophysiological components of type 2 diabetes [6-8], with the contributions of these factors thought to differ in Asians and whites. Most white people with type 2 diabetes present with IR [9], which is strongly associated with obesity, whereas most Japanese patients with type 2 diabetes do not have IR [10]. Furthermore, insulin secretion in Japanese individuals is reported to be less than half that in whites $[11,12]$. To date, however, few cohort studies have investigated insulin secretion in Asian populations [13, 14]. Because of the importance of investigating the impact of IIS and IR on the development of type 2 diabetes in various ethnic groups, we assessed the impact of both on the development of type 2 diabetes over a median of 4.0 years in a large-scale cohort of Japanese individuals, with insulin secretion and IR determined yearly using standard $75 \mathrm{~g}$ OGTTs.

\section{Methods}

Study design and participants The Saku study was designed to determine the incidence of and risk factors for type 2 diabetes among the Japanese population [15]. This study included community residents who underwent comprehensive medical check-ups for the prevention and early detection of various diseases, including diabetes, cardiovascular disease and cancer, at Saku Central Hospital, one of the core hospitals in the Nagano prefecture and located in Saku city of Nagano, Japan. The study involved residents of 15 cities (mainly Saku, Ueda, Nagano, Komoro and Tomi) in the Nagano prefecture who underwent a baseline comprehensive medical check-up over 2 days and 1 night between April 2006 and March 2007. The study protocol was in accordance with the Declaration of Helsinki and was approved by the Ethics Committee of Saku Central Hospital. Informed consent was obtained from each participant at each examination.

The cohort consisted of 4,318 individuals, aged 3069 years. Of these, 3,758 did not have diabetes at baseline, based on three criteria: (1) no history of diabetes, as determined by interviews conducted by the physicians; (2) fasting plasma glucose (FPG) concentration $<7.0 \mathrm{mmol} / \mathrm{l}$; and (3) $2 \mathrm{~h}$ post-load plasma glucose (PG) concentration $<11.1 \mathrm{mmol} / \mathrm{l}$. Of these 3,758 individuals, 3,093 (82.3\%) underwent at least one follow-up examination by the end of March 2011; we excluded 34 participants with missing data at baseline and/or annual follow-up examinations. Thus, a total of 3,059 individuals (1,754 men and 1,305 women), aged
30-69 years, were eligible for our analysis. Of these, 2,219 (72.5\%) underwent comprehensive annual medical check-ups every year for 4 years after the baseline examination.

Procedures All participants were fasted overnight (12 h), and had a standard $75 \mathrm{~g}$ OGTT in the morning. Blood samples were obtained at 0 (fasting), 30, 60 and $120 \mathrm{~min}$, with PG measured on all four occasions and serum insulin concentrations measured at 0 and $30 \mathrm{~min}$ in the clinical laboratory of Saku Central Hospital. Serum insulin concentrations were measured using a chemiluminescence enzyme immunoassay (Lumipulse Presto Insulin, Fujirebio, Tokyo, Japan). Blood glucose, HDL-cholesterol, LDL-cholesterol, serum triacylglycerol and uric acid concentrations were measured by enzymatic methods. Leukocyte counts were determined using automated cell counters. High-sensitive Creactive protein (hsCRP) concentrations were measured using the latex immunity turbidimetric method, and $\mathrm{HbA}_{1 \mathrm{c}}$ concentrations were measured by high-performance liquid chromatography. $\mathrm{HbA}_{1 \mathrm{c}}(\%)$ was estimated as a National Glycohemoglobin Standardization Program equivalent value $(\%)$ and calculated using the formula $\mathrm{HbA}_{1 \mathrm{c}}(\%)=\mathrm{HbA}_{1 \mathrm{c}}$ (Japan Diabetes Society, \%)+0.4\% [16]. $\mathrm{HbA}_{1 \mathrm{c}}(\mathrm{mmol} / \mathrm{mol})$ was calculated using the formula $\mathrm{HbA}_{1 \mathrm{c}}(\mathrm{mmol} / \mathrm{mol})=$ $10.39 \times \mathrm{HbA}_{1 \mathrm{c}}$ (Japan Diabetes Society, \%)-16.8.

Weight, height, waist circumference and body fat percentage were measured in the morning during the fasting state. BMI was calculated as the weight $(\mathrm{kg})$ divided by the height squared $\left(\mathrm{m}^{2}\right)$. Waist circumference was measured around the abdomen at the level of the navel at the late expiratory phase using a tape measure. Body fat percentage was evaluated by the bioelectric impedance method with an automatic scale. BP was measured by trained nurses using an automatic sphygmomanometer, with the individual in the sitting position after resting for at least $5 \mathrm{~min}$. Each checkup also included standard questionnaires on demographic characteristics, medical history, family history and healthrelated habits. Alcohol consumption (ethanol) was categorised as $0 \mathrm{~g} /$ week, $1-139 \mathrm{~g} /$ week, or $\geq 140 \mathrm{~g} /$ week, and exercise was categorised as $0 \mathrm{~min} /$ week, $1-119 \mathrm{~min} /$ week, or $\geq 120 \mathrm{~min} /$ week.

Definition of IIS and IR AUCs for type 2 diabetes (FPG $\geq 7.0 \mathrm{mmol} / 1 \mathrm{and} /$ or $2 \mathrm{~h}$ post-load $\mathrm{PG} \geq 11.1 \mathrm{mmol} / \mathrm{l}$ ) were calculated relative to insulin secretion and IR indices derived from the OGTT in 3,916 participants who were not receiving medical treatment for diabetes at baseline [17-24]. The AUCs of these indices, shown in Table 1, were crosssectionally evaluated using receiver operating characteristic (ROC) curves. The AUC of the insulinogenic index was highest at $0.825(95 \%$ CI $0.795,0.855)$ for insulin secretion, and the AUC of the HOMA-IR was highest at 0.778 (95\% CI $0.750,0.805$ ) for IR. 
Table 1 AUCs for ROCs for type 2 diabetes according to insulin secretion and IR indices derived from the OGTT: a cross-sectional analysis

\begin{tabular}{|c|c|c|c|}
\hline Index & Formula $^{\mathrm{a}}$ & Reference & AUC $(95 \% \mathrm{CI})$ \\
\hline \multicolumn{4}{|l|}{ Insulin secretion index ${ }^{b}$} \\
\hline Insulinogenic index & $\left(\right.$ Insulin $_{30}-$ Insulin $\left._{0}\right) /\left(\right.$ Glucose $_{30}-$ Glucose $\left._{0}\right)$ & {$[17]$} & $0.825(0.795,0.855)$ \\
\hline Corrected insulin response at $30 \mathrm{~min}$ & Insulin $_{30} /\left(\right.$ Glucose $_{30} \times\left(\right.$ Glucose $\left.\left._{30}-3.9\right)\right)$ & {$[18]$} & $0.813(0.784,0.842)$ \\
\hline 30 min insulin increment response & $\left(\right.$ Insulin $_{30}-$ Insulin $\left._{0}\right) /$ Glucose $_{30}$ & {$[19]$} & $0.798(0.762,0.834)$ \\
\hline Insulin ratio & Insulin $_{30} /$ Insulin $_{0}$ & {$[20]$} & $0.793(0.759,0.827)$ \\
\hline Insulin/glucose ratio at $30 \mathrm{~min}$ & Insulin $_{30} /$ Glucose $_{30}$ & {$[20]$} & $0.752(0.714,0.789)$ \\
\hline 30 min increase in insulin & Insulin $_{30}-$ Insulin $_{0}$ & {$[21]$} & $0.697(0.652,0.741)$ \\
\hline $30 \mathrm{~min}$ insulin & Insulin $_{30}$ & {$[20]$} & $0.629(0.583,0.675)$ \\
\hline HOMA for beta cell function & Insulin $_{0} \times 20 /\left(\text { Glucose }_{0}-3.5\right)^{\mathrm{d}}$ & {$[22]$} & $0.604(0.557,0.652)$ \\
\hline \multicolumn{4}{|l|}{ IR index ${ }^{b, c}$} \\
\hline HOMA-IR & Insulin $_{0} \times$ Glucose $_{0} / 22.5^{\mathrm{d}}$ & {$[22]$} & $0.778(0.750,0.805)$ \\
\hline Fasting serum insulin & Insulin $_{0}$ & {$[20]$} & $0.678(0.632,0.724)$ \\
\hline Hepatic IR index & $\mathrm{AUC}_{\text {insulin0-30 }} \times \mathrm{AUC}_{\text {glucose0-30 }} \mathrm{e}$ & {$[23]$} & $0.652(0.607,0.696)$ \\
\hline Insulin/glucose ratio at fasting & Insulin $_{0} /$ Glucose $_{0}$ & {$[20]$} & $0.590(0.543,0.638)$ \\
\hline
\end{tabular}

To determine the optimal cut-offs for the insulinogenic index and HOMA-IR, the Youden index (sensitivity+specificity -1) was calculated for each, with the optimal cut-off point taken as the value corresponding to the maximum Youden index. The optimal cut-off points for the insulinogenic index and HOMA-IR were $50.4 \mathrm{pmol} / \mathrm{mmol}(39.0 \mu \mathrm{U} / \mathrm{mg})$ and 1.7, respectively. These optimal cut-off values were similar to the reference value for IIS $(\leq 51.7 \mathrm{pmol} / \mathrm{mmol})$ and the normal value of HOMA-IR $(\leq 1.6)$ as defined by the Japan Diabetes Society [13, 25-27]. We therefore defined IIS as an insulinogenic index $\leq 51.7 \mathrm{pmol} / \mathrm{mmol}(40.0 \mu \mathrm{U} / \mathrm{mg})$, and IR as HOMA-IR $>1.6$. Participants in the study were classified into four categories: normal (insulinogenic index $>51.7 \mathrm{pmol} / \mathrm{mmol}$ and HOMA-IR $\leq 1.6$ ); isolated IIS (i-IIS; insulinogenic index $\leq 51.7 \mathrm{pmol} / \mathrm{mmol}$ and HOMA-IR $\leq 1.6$ ); isolated IR (i-IR; insulinogenic index $>51.7 \mathrm{pmol} / \mathrm{mmol}$ and HOMA-IR >1.6); and IIS plus IR (insulinogenic index $\leq 51.7 \mathrm{pmol} / \mathrm{mmol}$ and HOMA-IR $>1.6$ ).

Definition of type 2 diabetes incidence and follow-up Type 2 diabetes was defined using the 1999 WHO criteria [28], including $\mathrm{FPG} \geq 7.0 \mathrm{mmol} / 1$ and/or $2 \mathrm{~h}$ post-load $\mathrm{PG}$ $\geq 11.1 \mathrm{mmol} / 1$, or receiving medical treatment for type 2 diabetes. All 3,059 participants were followed up annually at Saku Central Hospital with comprehensive medical check-ups over 2 days and 1 night, including the $75 \mathrm{~g}$ OGTT, until they developed type 2 diabetes or until March
2011. Individuals not examined during follow-up were censored on the date of their last examination.

Statistical analysis The AUC of the PG (AUC glucose-120 $_{\text {- }}$ above fasting level during the OGTT was calculated by the trapezoidal method [29]. Differences in baseline characteristics among the normal, i-IIS, i-IR, and IIS plus IR groups were determined by: analysis of covariance with adjustments for age and sex for normally distributed continuous data; Kruskal-Wallis $\mathrm{H}$ tests for non-normally distributed continuous data (triacylglycerol, $\gamma$-glutamyltransferase, hsCRP concentrations and insulinogenic index); and $\chi^{2}$ tests for dichotomous and categorical data.

Cox proportional hazards regression was used to estimate the adjusted HR and 95\% CI for the incidence of type 2 diabetes in the i-IIS, i-IR, and IIS plus IR groups relative to the normal group. Multicollinearity between covariates was examined by calculating the mean and individual covariate variance inflation factors. Data were adjusted for age, sex, family history of diabetes (yes or no), current smoking (yes or no), alcohol consumption (0 g/week, 1-139 g/week or $\geq 140 \mathrm{~g} /$ week), and exercise (0 $\mathrm{min} /$ week, $1-119 \mathrm{~min} /$ week or $\geq 120 \mathrm{~min} /$ week). The assumptions required for proportional hazards were met, and these were assessed with graphs of $\log -\log$ plots. Population-attributable fraction (PAF) $[30,31]$ was calculated using the formula: $\mathrm{PAF}=p d[(\mathrm{HR}-1) / \mathrm{HR}]$, in which $p d$ was the proportion of individuals exposed to a risk 
factor and HR was the adjusted HR [32]. Multivariableadjusted HRs and 95\% CIs for type 2 diabetes incidence according to major risk factors for diabetes were calculated using Cox proportional hazards regression in the normal, i-IIS, i-IR, and IIS plus IR groups. To test interactions between each of the four groups and each risk factor, each interaction term was added to each model.

Participants were categorised into five groups: individuals who developed type 2 diabetes (i.e. incident cases) in the normal, i-IIS, i-IR and IIS plus IR groups; and individuals who maintained normal glucose regulation (i.e. controls). The $\log _{e}$-transformed insulinogenic index and HOMA-IR trajectories before diabetes onset or at the end of follow-up were calculated for these five groups. The observation period started (year 0) at the year of diabetes onset for incident cases and at the year of the last examination for controls. Participants were then traced backwards through baseline comprehensive medical check-ups. Repeated measurements of $\log _{e}$-transformed insulinogenic index or HOMA-IR were analysed using linear mixed models. The dependent measures were individual $\log _{e^{-}}$ transformed insulinogenic index and HOMA-IR values. The fixed effects included time, group, group-by-time, age (covariate) and sex (covariate), and individual was included as a random effect. When there was a significant interaction between group and time, stratified analysis by group was performed. Linear mixed models with Bonferroni adjustment for comparison of the -4 years with the 0 year was used. The dependent measures were individual $\log _{e^{-}}$ transformed insulinogenic index or HOMA-IR values. The fixed effects included time, age (covariate) and sex (covariate), and individual was included as a random effect.

All data were analysed using the SAS statistical package software (version 9.1; SAS Institute, Cary, NC, USA) and SPSS statistical software (version 17.0J; SPSS Japan, Tokyo, Japan). All reported $p$ values are two-tailed; those less than 0.05 were considered statistically significant.

\section{Results}

Baseline characteristics The mean age of the 3,059 participants was 55.7 years, and their mean BMI was $23.2 \mathrm{~kg} / \mathrm{m}^{2}$. At baseline, 1,550 individuals (50.7\%) were classified as normal, $900(29.4 \%)$ as having i-IIS, $505(16.5 \%)$ as having i-IR, and $104(3.4 \%)$ as having both IIS and IR. Table 2 shows the baseline characteristics of the four groups. All variables, except for occupation and exercise, differed significantly among the four groups. Of the four groups, individuals with i-IIS had the lowest BMI, waist circumference, body fat percentage, diastolic BP, LDL-cholesterol concentration, triacylglycerol concentration and leukocyte count, and the highest HDLcholesterol concentration.
Impact of baseline IIS and IR status on the development of type 2 diabetes The median follow-up was 4.0 years (total person-years 10,553), during which 219 individuals developed type 2 diabetes, including 26 defined as having type 2 diabetes by receiving medical treatment for this disease. As the youngest of these individuals was 40 years old at baseline, all incident cases were assumed to be type 2 diabetes. Table 3 presents the incidence rates, HRs and PAFs for the development of type 2 diabetes, based on baseline IIS and IR status. The multivariable-adjusted HRs for the incidence of type 2 diabetes in the i-IIS, i-IR, and IIS plus IR groups, relative to the normal group, were 8.27 (95\% CI 5.33, 12.83), 4.90 (95\% CI 2.94, 8.17) and 16.93 (95\% CI 9.80, 29.25), respectively. The PAFs for type 2 diabetes onset due to i-IIS, i-IR and IIS plus IR were $50.6 \%$ (95\% CI $46.7 \%$, $53.0 \%), 14.2 \%(95 \%$ CI $11.8 \%, 15.6 \%)$ and $12.9 \%$ (95\% CI $12.3 \%, 13.2 \%)$, respectively. We observed similar results when we analysed only the 2,219 participants who received annual comprehensive medical check-ups regularly for 4 years after the baseline examination.

Predictors for type 2 diabetes incidence Table 4 shows multivariable-adjusted HRs for type 2 diabetes in each group during the 4 year follow-up period. Age was a significant predictor of diabetes in the normal and i-IIS groups $\left(p_{\text {interaction }}=0.042\right)$, and family history of diabetes was a significant predictor of diabetes in the i-IIS group $\left(p_{\text {interaction }}=0.025\right)$. No interaction was observed between overweight/obesity and the four groups $\left(p_{\text {interaction }}=0.289\right)$. Sex was not a significant predictor of diabetes in any group.

Trajectories of insulin secretion and IR before type 2 diabetes onset Figure 1 shows the $\log _{e}$-transformed insulinogenic index and HOMA-IR trajectories before type 2 diabetes onset or at the end of follow-up. The linear mixed model showed significant interactions between group and time for both $\log _{e}$-transformed insulinogenic index $\left(p_{\text {interaction }}=0.021\right)$ and HOMA-IR $\left(p_{\text {interaction }}<0.001\right)$. Therefore, stratified analysis by group was performed. Incident cases in the i-IIS group showed a steady decrease in insulinogenic index during the 4 years before diabetes onset ( -4 vs 0 years: $p=0.012$ ); although their HOMA-IR values were low, they also showed a steady increase in HOMA-IR during the 4 years before diabetes onset ( -4 vs 0 years: $p=0.023)$. Incident cases in the i-IR group showed a steep increase in HOMA-IR values over time ( -4 vs 0 years: $p<0.001$ ), whereas the insulinogenic index followed a negative quadratic trajectory during the 4 years before diabetes onset ( -4 vs 0 years: $p=0.033$ ).

Subcohort with normal glucose regulation Electronic supplementary material (ESM) Tables 1, 2 and 3 and Fig. 1 shows the results of subcohorts with normal glucose 
Table 2 Baseline characteristics of the normal, i-IIS, i-IR and IIS plus IR groups between April 2006 and March 2007

\begin{tabular}{|c|c|c|c|c|c|}
\hline Characteristic & $\begin{array}{l}\text { Normal } \\
(n=1,550)\end{array}$ & $\begin{array}{l}\text { i-IIS } \\
(n=900)\end{array}$ & $\begin{array}{l}\text { i-IR } \\
(n=505)\end{array}$ & $\begin{array}{l}\text { IIS plus IR } \\
(n=104)\end{array}$ & $p$ value \\
\hline Age, years & $55.2(54.8,55.6)$ & $56.4(55.9,56.9)$ & $55.3(54.6,56.0)$ & $57.2(55.7,58.8)$ & 0.001 \\
\hline Men, $n(\%)$ & $787(51)$ & $581(65)$ & $319(63)$ & $67(64)$ & $<0.001$ \\
\hline Family history of diabetes, $n(\%)$ & $253(16)$ & $190(21)$ & $93(18)$ & $35(34)$ & $<0.001$ \\
\hline Occupation, $n(\%)$ & & & & & 0.24 \\
\hline Employee & $1,082(70)$ & $595(66)$ & $352(70)$ & $72(69)$ & \\
\hline Farmer & $161(10)$ & $114(13)$ & $42(8)$ & $10(10)$ & \\
\hline Homemaker & $198(13)$ & $109(12)$ & $66(13)$ & $13(13)$ & \\
\hline Without an occupation & $109(7)$ & $82(9)$ & $45(9)$ & $9(9)$ & \\
\hline Current smoker, $n(\%)$ & $240(16)$ & $220(24)$ & $72(14)$ & $31(30)$ & $<0.001$ \\
\hline Alcohol consumption (ethanol), $n(\%)$ & & & & & $<0.001$ \\
\hline $0 \mathrm{~g} /$ week & $577(37)$ & $246(27)$ & $168(33)$ & $33(32)$ & \\
\hline $1-139 \mathrm{~g} /$ week & $638(41)$ & $368(41)$ & $223(44)$ & $45(43)$ & \\
\hline$\geq 140 \mathrm{~g} /$ week & $335(22)$ & $286(32)$ & $114(23)$ & $26(25)$ & \\
\hline Exercise, $n(\%)$ & & & & & 0.08 \\
\hline $0 \mathrm{~min} /$ week & $737(48)$ & $408(45)$ & $266(53)$ & $50(48)$ & \\
\hline 1-119 $\mathrm{min} /$ week & $492(32)$ & $289(32)$ & $156(31)$ & $28(27)$ & \\
\hline$\geq 120 \mathrm{~min} /$ week & $321(21)$ & $203(23)$ & $83(16)$ & $26(25)$ & \\
\hline BMI, $\mathrm{kg} / \mathrm{m}^{2}$ & $22.7(22.6,22.9)$ & $22.3(22.1,22.5)$ & $25.6(25.4,25.8)$ & $25.1(24.6,25.6)$ & $<0.001$ \\
\hline Waist circumference, $\mathrm{cm}$ & $82.3(81.9,82.7)$ & $81.2(80.7,81.7)$ & $89.8(89.1,90.4)$ & $88.3(86.8,89.7)$ & $<0.001$ \\
\hline Body fat, $\%$ & $24.3(24.1,24.6)$ & $23.5(23.1,23.8)$ & $29.5(29.0,29.9)$ & $28.3(27.3,29.3)$ & $<0.001$ \\
\hline Systolic BP, mmHg & $118.7(117.9,119.4)$ & $119.0(117.9,119.4)$ & $123.0(121.7,124.4)$ & $123.7(120.8,126.7)$ & $<0.001$ \\
\hline Diastolic BP, mmHg & $73.2(72.7,73.8)$ & $72.4(71.7,73.1)$ & $76.5(75.6,77.4)$ & $76.8(74.8,78.8)$ & $<0.001$ \\
\hline HDL-cholesterol, mmol/1 & $1.51(1.49,1.53)$ & $1.58(1.56,1.61)$ & $1.33(1.30,1.36)$ & $1.40(1.34,1.47)$ & $<0.001$ \\
\hline LDL-cholesterol, mmol/1 & $3.22(3.18,3.26)$ & $3.18(3.13,3.23)$ & $3.37(3.31,3.44)$ & $3.23(3.09,3.37)$ & $<0.001$ \\
\hline Triacylglycerol, $\mathrm{mmol} / \mathrm{l}^{\mathrm{a}}$ & $0.97(0.71,1.34)$ & $0.94(0.69,1.40)$ & $1.43(1.02,1.95)$ & $1.34(1.00,1.82)$ & $<0.001$ \\
\hline$\gamma$-Glutamyltransferase, $\mu \mathrm{kat} / \mathrm{l}^{\mathrm{a}}$ & $0.35(0.23,0.62)$ & $0.40(0.27,0.73)$ & $0.57(0.38,1.02)$ & $0.61(0.37,1.18)$ & $<0.001$ \\
\hline Uric acid, $\mu \mathrm{mol} / 1$ & $321.2(317.9,324.5)$ & $323.7(319.4,328.1)$ & $352.2(346.4,357.9)$ & $348.9(336.2,361.6)$ & $<0.001$ \\
\hline Leucocyte count, $\times 10^{9} / 1$ & $5.17(5.10,5.24)$ & $5.15(5.06,5.24)$ & $5.71(5.59,5.82)$ & $5.64(5.39,5.90)$ & $<0.001$ \\
\hline HsCRP, $\mu \mathrm{g} / \mathrm{ml}^{\mathrm{a}}$ & $0.4(0.2,0.8)$ & $0.4(0.2,0.9)$ & $0.7(0.4,1.3)$ & $0.7(0.4,1.1)$ & $<0.001$ \\
\hline Insulinogenic index, $\mathrm{pmol} / \mathrm{mmol}^{\mathrm{a}}$ & $95.8(70.0,153.7)$ & $33.6(23.0,42.6)$ & $118.2(81.3,178.7)$ & $38.8(28.0,47.0)$ & $<0.001$ \\
\hline HOMA-IR & $0.91(0.88,0.94)$ & $0.77(0.74,0.81)$ & $2.40(2.35,2.45)$ & $2.23(2.12,2.34)$ & $<0.001$ \\
\hline Fasting serum insulin, $\mathrm{pmol} / 1$ & $27.3(26.5,28.0)$ & $22.5(21.6,23.5)$ & $67.5(66.2,68.8)$ & $59.7(56.8,62.6)$ & $<0.001$ \\
\hline $30 \mathrm{~min}$ serum insulin, $\mathrm{pmol} / 1$ & $313.9(305.5,322.3)$ & $159.8(148.8,170.8)$ & $496.9(482.3,511.5)$ & $226.4(194.2,258.6)$ & $<0.001$ \\
\hline $\mathrm{HbA}_{1 \mathrm{c}}, \%$ & $5.47(5.45,5.48)$ & $5.55(5.53,5.57)$ & $5.60(5.57,5.63)$ & $5.77(5.71,5.84)$ & $<0.001$ \\
\hline $\mathrm{HbA}_{1 \mathrm{c}}, \mathrm{mmol} / \mathrm{mol}$ & $36.3(36.1,36.4)$ & $37.2(36.9,37.4)$ & $37.7(37.4,38.0)$ & $39.6(38.9,40.3)$ & $<0.001$ \\
\hline $\mathrm{FPG}, \mathrm{mmol} / 1$ & $5.36(5.34,5.39)$ & $5.48(5.45,5.51)$ & $5.72(5.68,5.76)$ & $6.00(5.92,6.08)$ & $<0.001$ \\
\hline $30 \mathrm{~min} P G, \mathrm{mmol} / \mathrm{l}$ & $8.02(7.94,8.10)$ & $9.04(8.93,9.14)$ & $8.98(8.84,9.12)$ & $9.87(9.56,10.17)$ & $<0.001$ \\
\hline $60 \mathrm{~min} P G, \mathrm{mmol} / 1$ & $7.13(7.03,7.22)$ & $9.23(9.11,9.36)$ & $8.57(8.40,8.74)$ & $10.76(10.39,11.13)$ & $<0.001$ \\
\hline $2 \mathrm{~h} \mathrm{PG}, \mathrm{mmol} / \mathrm{l}$ & $6.27(6.20,6.33)$ & $6.78(6.69,6.87)$ & $6.94(6.82,7.06)$ & $7.63(7.37,7.88)$ & $<0.001$ \\
\hline $\mathrm{AUC}_{\text {glucose } 0-120}, \mathrm{mmol} \times \mathrm{min} / 1$ & $191.2(184.8,197.5)$ & $320.2(311.9,328.5)$ & $265.5(254.5,276.6)$ & $384.8(360.3,409.2)$ & $<0.001$ \\
\hline
\end{tabular}

Normal, insulinogenic index $>51.7$, HOMA-IR $\leq 1.6$; i-IIS, insulinogenic index $\leq 51.7$, HOMA-IR $\leq 1.6$; i-IR, insulinogenic index $>51.7$, HOMA-IR $>1.6$; IIS plus IR, insulinogenic index $\leq 51.7$, HOMA-IR $>1.6$

Dichotomous and categorical data are reported as number $(\%)$

Continuous, normally distributed data are reported as age- and sex-adjusted mean $(95 \% \mathrm{CI})$

${ }^{a}$ Continuous, non-normally distributed data are reported as median (25th, 75 th percentile) 
Table 3 Incidence rates, HRs and PAFs for the development of type 2 diabetes, according to baseline IIS and IR status

\begin{tabular}{lllll}
\hline Variable & $\begin{array}{l}\text { Normal } \\
(n=1,550)\end{array}$ & $\begin{array}{l}\text { i-IIS } \\
(n=900)\end{array}$ & $\begin{array}{l}\text { i-IR } \\
(n=505)\end{array}$ & $\begin{array}{l}\text { IIS plus IR } \\
(n=104)\end{array}$ \\
\hline Incident cases (n/person-years) & $24 / 5,447$ & $126 / 3,032$ & $39 / 1,748$ & $30 / 326$ \\
Incidence rate (/1,000 person-years) & 4.4 & 41.6 & 22.3 & 92.0 \\
HR (95\% CI) & & & & \\
Model 1 & 1.0 & $8.56(5.53,13.27)$ & $4.79(2.88,7.97)$ & $18.44(10.77,31.59)$ \\
Model 2 & 1.0 & $8.27(5.33,12.83)$ & $4.90(2.94,8.17)$ & $16.93(9.80,29.25)$ \\
PAF (95\% CI),$\%$ & - & $50.6(46.7,53.0)$ & $14.2(11.8,15.6)$ & $12.9(12.3,13.2)$ \\
\hline
\end{tabular}

Model 1, adjusted for age and sex

Model 2, adjusted for age, sex, family history of diabetes (yes or no), current smoking (yes or no), alcohol consumption ( $0 \mathrm{~g} / \mathrm{week}, 1-139 \mathrm{~g} / \mathrm{week}$ or $\geq 140 \mathrm{~g} /$ week $)$, and exercise ( $0 \mathrm{~min} /$ week, $1-119 \mathrm{~min} /$ week or $\geq 120 \mathrm{~min} /$ week $)$

Normal, insulinogenic index $>51.7$, HOMA-IR $\leq 1.6$; i-IIS, insulinogenic index $\leq 51.7$, HOMA-IR $\leq 1.6$; i-IR, insulinogenic index $>51.7$, HOMA-IR $>1.6$; IIS plus IR, insulinogenic index $\leq 51.7$, HOMA-IR $>1.6$

${ }^{a}$ PAF (\%) was calculated using multivariable-adjusted HR (Model 2); for example, the PAF of individuals with i-IIS was calculated as (126/ $219) \times(8.27-1.00) / 8.27 \times 100=50.6 \%$

regulation (FPG $<6.1 \mathrm{mmol} / 1$ and $2 \mathrm{~h} \mathrm{PG}<7.8 \mathrm{mmol} / \mathrm{l}$ ) [23]. At baseline, 1,338 individuals (58.3\%) were classified as normal, $609(26.5 \%)$ as having i-IIS, $310(13.5 \%)$ as having i-IR and $39(1.7 \%)$ as having both IIS and IR. During 8,055 person-years of follow-up, 54 individuals developed type 2 diabetes, with 29 (53.7\%) having i-IIS at baseline. Relative to the normal group, the multivariable-adjusted HRs for type 2 diabetes in the i-IIS, i-IR, and IIS plus IR groups were 6.21 (95\% CI 2.92, 13.22), 5.16 (95\% CI 2.08, 12.78) and 19.69 (95\% CI 6.70, 57.83), respectively.

\section{Discussion}

This large-scale, community-based cohort study clearly shows the impact of IIS and IR on the incidence of type 2 diabetes in a Japanese population. Our main finding was that, after adjusting for confounding factors, the HRs for type 2 diabetes were 8.27 in the i-IIS group, 4.90 in the i-IR group and 16.93 in the IIS plus IR group when compared with the normal group. Notably, 1.8-fold more individuals in our cohort had i-IIS than i-IR at baseline. In addition, of the 219 incident cases, $126(57.5 \%)$ had i-IIS at baseline. Thus, the PAF (50.6\%) of type 2 diabetes onset due to i-IIS was higher than that due to i-IR or IIS plus IR.

Our findings indicate that IIS had a strong impact on the development of type 2 diabetes in this Japanese population. Approximately $50 \%$ of cases of incident type 2 diabetes in our population could be attributed to i-IIS, a finding that may explain, at least in part, the high prevalence of type 2 diabetes in Asians with low BMI. Individuals in our i-IIS group were characterised by low BMI and small waist circumference.

Table 4 Factors predicting the development of type 2 diabetes in the normal, i-IIS, i-IR, and IIS plus IR groups during a 4 year follow-up period

\begin{tabular}{|c|c|c|c|c|c|}
\hline \multirow[t]{2}{*}{ Adjusted variable } & \multicolumn{5}{|c|}{ Adjusted HR (95\% CI) } \\
\hline & $\begin{array}{l}\text { Normal } \\
(n=1,550)\end{array}$ & $\begin{array}{l}\text { i-IIS } \\
(n=900)\end{array}$ & $\begin{array}{l}\text { i-IR } \\
(n=505)\end{array}$ & $\begin{array}{l}\text { IIS plus IR } \\
(n=104)\end{array}$ & $p$ value for interaction \\
\hline $\begin{array}{l}\text { Age: } 30-59 \text { years } \\
\text { Age: } 60-69 \text { years }\end{array}$ & $\begin{array}{l}1.0 \\
4.80(2.00,11.53)\end{array}$ & $\begin{array}{l}1.0 \\
1.99(1.39,2.85)\end{array}$ & $\begin{array}{l}1.0 \\
1.42(0.70,2.89)\end{array}$ & $\begin{array}{l}1.0 \\
1.19(0.56,2.53)\end{array}$ & 0.042 \\
\hline $\begin{array}{l}\text { Sex: women } \\
\text { Sex: men }\end{array}$ & $\begin{array}{l}1.0 \\
0.66(0.23,1.84)\end{array}$ & $\begin{array}{l}1.0 \\
1.21(0.75,1.95)\end{array}$ & $\begin{array}{l}1.0 \\
2.04(0.88,4.73)\end{array}$ & $\begin{array}{l}1.0 \\
1.18(0.44,3.18)\end{array}$ & 0.584 \\
\hline $\begin{array}{l}\text { Family history of diabetes: no } \\
\text { Family history of diabetes: yes }\end{array}$ & $\begin{array}{l}1.0 \\
0.73(0.22,2.48)\end{array}$ & $\begin{array}{l}1.0 \\
1.89(1.29,2.76)\end{array}$ & $\begin{array}{l}1.0 \\
0.73(0.31,1.76)\end{array}$ & $\begin{array}{l}1.0 \\
0.91(0.41,2.03)\end{array}$ & 0.025 \\
\hline $\begin{array}{l}\mathrm{BMI}<25.0 \mathrm{~kg} / \mathrm{m}^{2} \\
\mathrm{BMI} \geq 25.0 \mathrm{~kg} / \mathrm{m}^{2}\end{array}$ & $\begin{array}{l}1.0 \\
0.76(0.26,2.28)\end{array}$ & $\begin{array}{l}1.0 \\
1.48(0.95,2.26)\end{array}$ & $\begin{array}{l}1.0 \\
2.16(1.05,4.46)\end{array}$ & $\begin{array}{l}1.0 \\
1.22(0.57,2.59)\end{array}$ & 0.289 \\
\hline
\end{tabular}

Adjusted for all variables in table plus current smoking (yes or no), alcohol consumption ( $0 \mathrm{~g} /$ week, $1-139 \mathrm{~g} /$ week or $\geq 140 \mathrm{~g} /$ week), and exercise (0 $\mathrm{min} /$ week, $1-119 \mathrm{~min} /$ week or $\geq 120 \mathrm{~min} /$ week)

Normal, insulinogenic index $>51.7$, HOMA-IR $\leq 1.6$; i-IIS, insulinogenic index $\leq 51.7$, HOMA-IR $\leq 1.6$; i-IR, insulinogenic index $>51.7$, HOMA-IR $>1.6$; IIS plus IR, insulinogenic index $\leq 51.7$, HOMA-IR $>1.6$ 

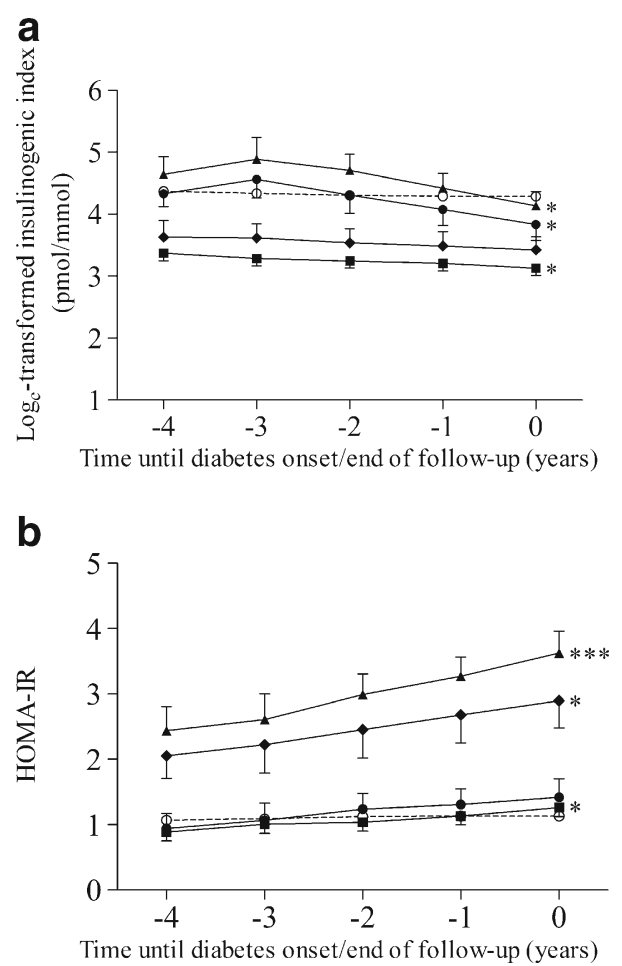

Fig. $1 \log _{e}$-transformed insulinogenic index (a) and HOMA-IR (b) trajectories before type 2 diabetes onset or at the end of follow-up among incident cases in the normal $(n=24$; black circles), i-IIS ( $n=$ 126 ; black squares), i-IR ( $n=39$; black triangles) and IIS plus IR $(n=$ 30 ; black diamonds) groups, and in individuals who maintained normal glucose regulation $(n=2,840$; white circles). Repeated measurements of $\log _{e}$-transformed insulinogenic index and HOMA-IR were analysed using a linear mixed model with Bonferroni adjustment for comparison of the -4 years with the 0 year. Each point represents the age- and sexadjusted mean and the error bars represent $95 \% \mathrm{CI} ; 5 \mathrm{pmol} / \mathrm{mmol}$ $\left(\log _{e}\right.$-transformed insulinogenic index $)=150 \mathrm{pmol} / \mathrm{mmol}$ (insulinogenic index); $4 \mathrm{pmol} / \mathrm{mmol}=55 \mathrm{pmol} / \mathrm{mmol} ; 3 \mathrm{pmol} / \mathrm{mmol}=$ $20 \mathrm{pmol} / \mathrm{mmol}$. ${ }^{*} p<0.05$ and ${ }^{* * * *} p<0.001$ for -4 vs 0 years

Moreover, overweight/obesity was not a predictor of diabetes in our i-IIS group. Predictors of diabetes in the i-IIS group were age and family history of diabetes. Variants in the $K C N Q 1$ gene have been reported to increase the risk of future type 2 diabetes, mostly in Asian individuals [33, 34]. The relative risk of type 2 diabetes for Japanese carriers of the KCNJ15 risk allele was 1.76 , increasing to 2.54 in individuals with a BMI less than $24 \mathrm{~kg} / \mathrm{m}^{2}$ [35]. These $K C N Q 1$ and $K C N J 15$ variants have been reported to affect the development of type 2 diabetes by impairing beta cell function [33, 34, 36, 37]. These findings suggest that the number of individuals with IIS may be high in Asian populations and that the development of type 2 diabetes in many Asians may be due to IIS.

Approximately $15 \%$ of the incidence of type 2 diabetes in our cohort could be attributed to i-IR and approximately $13 \%$ to IIS plus IR. Although the PAF of type 2 diabetes onset due to i-IR or IIS plus IR was lower than that due to i-IIS, we found that individuals in our i-IR and IIS plus IR groups had high BMI, waist circumference, body fat percentage, systolic BP, diastolic BP and leukocyte counts, and high concentrations of triacylglycerol, LDL-cholesterol, $\gamma$-glutamyltransferase, uric acid and hsCRP. Therefore, additional studies are needed to determine the impact of IIS and IR on the risk for macrovascular and microvascular complications.

There were significant interactions between group and time in both $\log _{e}$-transformed insulinogenic index and HOMA-IR: i.e. the patterns of the trajectories of their insulinogenic index and HOMA-IR differed in the five groups. In incident cases in the i-IIS group, HOMA-IR values were low, but a low insulin-secreting ability was unlikely to compensate for a slight increase in IR. The trajectories of the insulinogenic index and HOMA-IR in incident cases in the i-IIS group may be a pattern specific to Asian populations. In contrast, incident cases in the i-IR group showed a pattern similar to that of the Whitehall II Study, conducted in the UK [38]. Additional long-term studies are needed to determine the natural history of insulin secretion and IR in Asian populations.

In normoglycaemic individuals, the HRs for type 2 diabetes were 6.21 in the i-IIS group, 5.16 in the i-IR group and 19.69 in the IIS plus IR group when compared with the normal group. IR has been found to predict diabetes risk only in normoglycaemic individuals with family history of diabetes, and not in those without [39]. In the present study, although IR was a risk factor for type 2 diabetes in both normoglycaemic individuals with family history of diabetes and those without, the HR for IR was higher in those with a family history of diabetes than in those without.

The strengths of the present study include its large-scale, community-based cohort, which consisted of residents of many cities throughout Nagano prefecture. Furthermore, we screened all participants for type 2 diabetes every year for 4 years using the $75 \mathrm{~g}$ OGTT. The $12 \mathrm{~h}$ overnight fast before OGTT was managed by hospitalising participants the day before the test.

This study, however, also had several limitations. First, the estimates of insulin secretion and IR were made using calculations based on the OGTT, not by the 'gold standard' test, the glucose-clamp technique. However, clamping is not feasible in large-scale epidemiological studies, and we believe that proxy measures are reliable in large datasets. In cross-sectional ROC analysis, the AUCs for the insulinogenic index and HOMA-IR were 0.825 and 0.778 , respectively. The insulinogenic index has been used previously in clinical studies [13, 17, 40], and HOMA-IR has also been extensively validated [41, 42].

Second, there may have been a possibility of selection bias, as the participants in this study were individuals who underwent routine comprehensive medical check-ups. Although these check-ups are generally expensive in Japan, those at Saku Central Hospital are relatively inexpensive or free, because administrations and employers subsidise their costs. Therefore, many community residents undergo 
these examinations, and the rates of diabetes and overweight/obesity in our cohort were similar to those observed in the general Japanese population [43]. Third, individuals who did not undergo annual comprehensive medical check-ups after their baseline examinations were excluded from our analysis. As individuals who developed severe diseases or died during the follow-up period were not assessed, selection bias is possible. However, baseline characteristics such as age, sex, BMI, FPG, $2 \mathrm{~h} \mathrm{PG}$, and IIS and IR status did not differ significantly between individuals who were eligible for our analysis and individuals who did not undergo comprehensive medical check-ups after their baseline examinations (data not shown).

In conclusion, this study showed clear evidence of the impact of IIS and IR on the incidence of type 2 diabetes and the trajectories of insulin secretion and IR before type 2 diabetes onset in a Japanese population. The PAF of type 2 diabetes onset due to i-IIS was the highest (50.6\%), indicating that IIS had a strong impact on the incidence of type 2 diabetes in this population. As Japanese individuals have low insulinsecreting ability [11], assessments of IIS are necessary so that groups at high risk of developing type 2 diabetes are not overlooked. Our findings may also be applicable to other Asian populations with similar genetic background.

Acknowledgements We thank Ryuichi Kikkawa (Shiga University of Medical Science, Shiga, Japan), Tomonori Okamura (Keio University, Tokyo, Japan) and Yoshihiro Miyamoto (National Cerebral and Cardiovascular Center, Osaka, Japan) for their advice on this paper.

Funding AM is a recipient of a Grant-in-Aid for Japan Society for the Promotion of Science Fellowship. This study was funded by grants from the Ministry of Health, Labor and Welfare, Japan.

Duality of interest The authors declare that there is no duality of interest associated with this manuscript.

Contribution statement AM, YT, KD, SM and SW designed the study. AM, YT, KD and SM contributed to acquisition of the data. AM, YT, and SM performed the analyses. AM wrote the first draft of the paper, and YT, KD, SM, YO, NM and SW contributed to the interpretation of data and critical revision of the manuscript. All authors were involved in the writing of the manuscript and approved the final version of this article.

\section{References}

1. Shaw JE, Sicree RA, Zimmet PZ (2010) Global estimates of the prevalence of diabetes for 2010 and 2030. Diabetes Res Clin Pract 87:4-14

2. Lee JW, Brancati FL, Yeh HC (2011) Trends in the prevalence of type 2 diabetes in Asians versus whites: results from the United States National Health Interview Survey, 1997-2008. Diabetes Care 34:353-357
3. Nelson KM, Reiber G, Boyko EJ (2002) Diet and exercise among adults with type 2 diabetes: findings from the third national health and nutrition examination survey (NHANES III). Diabetes Care 25:1722-1728

4. Davis TM, Cull CA, Holman RR, U.K. Prospective Diabetes Study (UKPDS) Group (2001) Relationship between ethnicity and glycemic control, lipid profiles, and blood pressure during the 9 years of type 2 diabetes: U.K. Prospective Diabetes Study (UKPDS 55). Diabetes Care 24:1167-1174

5. Sone H, Katagiri A, Ishibashi S et al (2002) Effects of lifestyle modifications on patients with type 2 diabetes: the Japan Diabetes Complications Study (JDCS) study design, baseline analysis and three year-interim report. Horm Metab Res 34:509-515

6. Kahn SE (2003) The relative contribution of insulin resistance and beta-cell dysfunction to the pathophysiology of type 2 diabetes. Diabetologia 46:3-19

7. Martin BC, Warram JH, Krolewski AS, Bergman RN, Soeldner JS, Kahn CR (1992) Role of glucose and insulin resistance in development of type 2 diabetes mellitus: results of a 25 -year follow-up study. Lancet 340:925-929

8. Warram JH, Martin BC, Krolewski AS, Soeldner JS, Kahn CR (1990) Slow glucose removal rate and hyperinsulinemia precede the development of type II diabetes in the offspring of diabetic parents. Ann Intern Med 113:909-915

9. Welch S, Gebhart SSP, Bergman RN (1990) Minimal model analysis of intravenous glucose tolerance test-derived insulin sensitivity in diabetic subjects. J Clin Endocrinol Metab 71:1508-1518

10. Taniguchi A, Nakai Y, Fukushima M et al (1992) Pathogenic factors responsible for glucose intolerance in patients with NIDDM. Diabetes 41:1540-1546

11. Fukushima M, Usami M, Ikeda M et al (2004) Insulin secretion and insulin sensitivity at different stages of glucose tolerance: a cross-sectional study of Japanese type 2 diabetes. Metabolism 53:831-835

12. Tripathy D, Carlsson M, Almgren P et al (2000) Insulin secretion and insulin sensitivity in relation to glucose tolerance: lessons from the Botnia Study. Diabetes 49:975-980

13. Kosaka K, Kuzuya T, Yoshinaga H, Hagura R (1996) A prospective study of health check examinees for the development of noninsulin-dependent diabetes mellitus: relationship of the incidence of diabetes with the initial insulinogenic index and degree of obesity. Diabet Med 13:S120-S126

14. Ito C (1990) Influence of obesity on glucose tolerance and IRI response. Diabetes Res Clin Pract 10:S231-S237

15. Morimoto A, Tatsumi Y, Deura K, Mizuno S, Ohno Y, Watanabe S (2012) Impact of cigarette smoking on impaired insulin secretion and insulin resistance in Japanese men: The Saku Study. J Diabetes Invest. doi:10.1111/jdi.12019

16. Kashiwagi A, Kasuga M, Araki E et al (2012) International clinical harmonization of glycated hemoglobin in Japan: from Japan Diabetes Society to National Glycohemoglobin Standardization Program values. J Diabetes Invest 3:39-40

17. Seltzer HS, Allen EW, Herron AL Jr, Brennan MT (1967) Insulin secretion in response to glycemic stimulus: relation of delayed initial release to carbohydrate intolerance in mild diabetes mellitus. J Clin Invest 46:323-334

18. Sluiter WJ, Erkelens DW, Reitsma WD, Doorenbos H (1976) Glucose tolerance and insulin release, a mathematical approach I. Assay of the beta-cell response after oral glucose loading. Diabetes 25:241-244

19. Wareham NJ, Phillips DIW, Byrne CD, Hales CN (1995) The 30 minute insulin increment response in an oral glucose tolerance test as a measure of insulin secretion. Diabet Med 12:931

20. Hanson RL, Pratley RE, Bogardus C et al (2000) Evaluation of simple indices of insulin sensitivity and insulin secretion for use in epidemiologic studies. Am J Epidemiol 151:190-198 
21. Ahrén B, Larsson H (2002) Quantification of insulin secretion in relation to insulin sensitivity in nondiabetic postmenopausal women. Diabetes 51:S202-S211

22. Matthews DR, Hosker JP, Rudenski AS, Naylor BA, Treacher DF, Turner RC (1985) Homeostasis model assessment: insulin resistance and $\beta$-cell function from fasting plasma glucose and insulin concentrations in man. Diabetologia 28:412-419

23. Abdul-Ghani MA, Matsuda M, Balas B, DeFronzo RA (2007) Muscle and liver insulin resistance indexes derived from the oral glucose tolerance test. Diabetes Care 30:89-94

24. Katz A, Nambi SS, Mather K et al (2000) Quantitative insulin sensitivity check index: a simple, accurate method for assessing insulin sensitivity in humans. J Clin Endocrinol Metab 85:2402-2410

25. Nakai Y, Nakaishi S, Kishimoto H et al (2002) The threshold value for insulin resistance on homeostasis model assessment of insulin sensitivity. Diabet Med 19:346-347

26. The Japan Diabetes Society (2010) Evidence-based Practice Guideline for the Treatment of Diabetes in Japan 2010. Nankodo, Tokyo [guideline in Japanese]

27. The Japan Diabetes Society (2010) Treatment guide for diabetes 2010. Bunkodo, Tokyo [guide in Japanese]

28. World Health Organization (1999) Report of a WHO consultation: definition, diagnosis and classification of diabetes mellitus and its complications: Part 1. Diagnosis and classification of diabetes mellitus. Department of Noncommunicable Disease Surveillance. Geneva, WHO

29. Wolever TM, Jenkins DJ (1986) The use of the glycemic index in predicting the blood glucose response to mixed meals. Am J Clin Nutr 43:167-172

30. Winell K, Pietilä A, Niemi M, Reunanen A, Salomaa V (2011) Trends in population attributable fraction of acute coronary syndrome and ischaemic stroke due to diabetes in Finland. Diabetologia 54:2789-2794

31. Kokubo Y, Kamide K, Okamura T (2008) Impact of high-normal blood pressure on the risk of cardiovascular disease in a Japanese urban cohort: the Suita study. Hypertension 52:652-659

32. Rockhill B, Newman B, Weinberg C (1998) Use and misuse of population attributable fractions. Am J Public Health $88: 15-19$
33. Hu C, Wang C, Zhang R et al (2009) Variations in KCNQ1 are associated with type 2 diabetes and beta cell function in a Chinese population. Diabetologia 52:1322-1325

34. Jonsson A, Isomaa $\mathrm{B}$, Tuomi $\mathrm{T}$ et al (2009) A variant in the KCNQ1 gene predicts future type 2 diabetes and mediates impaired insulin secretion. Diabetes 58:2409-2413

35. Okamoto K, Iwasaki N, Nishimura C et al (2010) Identification of $\mathrm{KCNJ} 15$ as a susceptibility gene in Asian patients with type 2 diabetes mellitus. Am J Hum Genet 86:54-64

36. van Vliet-Ostaptchouk JV, van Haeften TW, Landman GW et al (2012) Common variants in the type 2 diabetes KCNQ1 gene are associated with impairments in insulin secretion during hyperglycaemic glucose clamp. PLoS One 7:e32148

37. Okamoto K, Iwasaki N, Doi K et al (2012) Inhibition of glucose-stimulated insulin secretion by KCNJ15, a newly identified susceptibility gene for type 2 diabetes. Diabetes 61:1734-1741

38. Tabák AG, Jokela M, Akbaraly TN, Brunner EJ, Kivimäki M, Witte DR (2009) Trajectories of glycemia, insulin sensitivity and insulin secretion preceding the diagnosis of type 2 diabetes: the Whitehall II Study. Lancet 373:2215-2221

39. Goldfine AB, Bouche C, Parker RA et al (2003) Insulin resistance is a poor predictor of type 2 diabetes in individuals with no family history of disease. Proc Natl Acad Sci USA 100:2724-2729

40. Jensen CC, Cnop M, Hull RL, Fujimoto WY, Kahn SE, American Diabetes Association GENNID, Group S (2002) $\beta$ Cell function is a major contributor to oral glucose tolerance in high-risk relatives of four ethnic groups in the U.S. Diabetes 51:2170-2178

41. Bonora E, Targher G, Alberiche M et al (2000) Homeostasis model assessment closely mirrors the glucose clamp technique in the assessment of insulin sensitivity. Diabetes Care 23:57-63

42. Wallace TM, Levy JC, Matthews DR (2004) Use and abuse of HOMA modeling. Diabetes Care 27:1487-1495

43. Ministry of Health, Labor and Welfare (2005) National Health and Nutrition Examination Survey [in Japanese]. Available from www.mhlw.go.jp/bunya/kenkou/eiyou07/d1/01-03.pdf, accessed 20 October 2012 